\title{
Improving the clarity and con- sistency of advice on missed contraceptive pills in the UK: response from the CEU
}

The Clinical Effectiveness Unit (CEU) welcomes the opportunity to respond to Ms Lizzie Greed and Dr Ailsa Gebbie's letter on the subject of 'Improving the clarity and consistency of advice on missed contraceptive pills in the UK'. ${ }^{1}$

As highlighted by Ms Greed and Dr Gebbie, the guidance offered by the Faculty of Sexual and Reproductive Healthcare (FSRH) and manufacturers of combined oral contraceptives (COCs) has differed. In 2005 the FSRH CEU published guidance on missed pills ${ }^{2}$ based on revised recommendations published by the World Health Organization. ${ }^{3}$ The rules had differing advice depending on the strength of the pill $(\geq 30$ or $<30 \mu$ g ethinylestradiol). ${ }^{2}$ However, the pharmaceutical companies that manufactured COCs continued to advise the original missed pill rules in patient information leaflets.

In 2010, the UK Medicines and Healthcare products Regulatory Agency (MHRA) identified the need for clearer, more consistent missed pill rules. The MHRA asked the FSRH CEU to review its advice on missed pills with the aim of agreeing new harmonised recommendations based on advice from the Commission on Human Medicines. The revised rules drawn up by the MHRA and approved by the FSR $\mathrm{H}^{4}$ and the Family Planning Association (FPA) ${ }^{5}$ apply to all COCs with an estrogen dose of at least $20 \mu \mathrm{g}$ (with the exception of the estradiol valerate-containing pill, Qlaira ${ }^{\circledR}$ ) (Bayer Schering Pharma), whether monophasic or phasic and including every day preparations.

The scientific evidence base has not changed significantly since publication of the missed pill rules in 2005; however, anecdotal evidence suggested that women and health professionals found the rules complicated and difficult to use. It is hoped that these revised rules and the agreement of all agencies involved will ensure consistency in the advice being given to women.

The MHRA have published a statement on their website ${ }^{6}$ and the FSRH announced the publication of these new rules at the Faculty's Annual Scientific Meeting in Liverpool in May 2011. The CEU have published a statement in relation to the new rules, which can be found on the Faculty website. ${ }^{4}$ 
Julie Craik, BSc, MSc

Researcher, Faculty of Sexual and Reproductive Healthcare, Clinical Effectiveness Unit, Sandyford, Glasgow, UK; julie.craik2@ggc.scot.nhs.uk

Competing interests None.

J Fam Plann Reprod Health Care 2011;37:187-188 doi:10.1136/jprhc-2011-0147

\section{REFERENCES}

1. Greed E, Gebbie A. Improving the clarity and consistency of advice on missed contraceptive pills in the UK [Letter]. J Fam Plann Reprod Health Care 2011:37:187.

2. Faculty of Sexual and Reproductive Healthcare Clinical Effectiveness Unit Combined Oral Contraception - Missed Pills. January 2004 (updated April 2005). http:// www.fsrh.org/pdfs/archive/MissedPills05.pdf [accessed 13 May 2011].

3. World Health Organization. Selected Practice Recommendations for Contraceptive Use [Update]. 2004. http://www.who.int/ reproductive-health/publications/spr 2/index.html [accessed 13 May 2011].

4. Faculty of Sexual and Reproductive Healthcare Clinical Effectiveness Unit. CEU Statement (May 2011): Missed Pill Recommendations. 2011. http://www.fsrh.org/ pdfs/CEUStatementMissedPills.pdf [accessed 13 May 2011].

5. Family Planning Association. The Combined Pill: Your Guide. 2011. http://www.fpa.org.uk/ helpandadvice/contraception/combinedpill [accessed 13 May 2011].

6. Medicines and Healthcare products Regulatory Authority. MHRA UK Public Assessment Report. Combined Oral Contraceptives (The Pill): When to Start Taking The Pill, and Missed Pill Advice. 2011. http:// www.mhra.gov.uk/Safetyinformation/ Generalsafetyinformationandadvice/ Product-specificinformationandadvice/ Product-specificinformationandadvice- $\mathrm{G}-\mathrm{L} /$ Hormonalcontraceptives/index.htm [accessed 13 May 2011]. 